\title{
JURISPRUDENCIA AMBIENTAL EN LA RIOJA (SEGUNDO SEMESTRE 2018)
}

\author{
María del Carmen Bolaño PiñeIro
}

Doctora en Derecho. Profesora Adjunta de Derecho Administrativo Universidad del País Vasco / Euskal Herriko Unibertsitatea 
Sumario. 1. Panorámica general. 2. Vertidos de aguas residuales. 3. Caza.

\section{PANORÁMICA GENERAL}

Como viene siendo habitual, son escasas las sentencias dictadas en materia medioambiental por el Tribunal Superior de Justicia de La Rioja en el semestre objeto de recopilación. En esta crónica se va a dar cuenta de tres: 1) una sentencia por la cual se declara ajustada a derecho una resolución de la Confederación Hidrográfica del Ebro en la que se sanciona al Consorcio de Aguas y Residuos de La Rioja, por el incumplimiento de la autorización de vertidos de aguas residuales al superar el volumen máximo diario autorizado a lo largo de todo el año, y por la realización de vertidos contaminantes no autorizados en época de vendimia; y 2) dos sentencias que dirimen cuestiones relacionadas con dos procedimientos sancionadores en materia de caza.

\section{VERTIDOS DE AGUAS RESIDUALES}

En la sentencia del Tribunal Superior de Justicia de La Rioja 344/2018, de 5 de julio, se resuelve el recurso contra la resolución de la Confederación Hidrográfica del Ebro de 10 de abril de 2017, que desestimaba el recurso de reposición contra la resolución de 11 de noviembre de 2016, por la que se imponía una sanción de multa de $4.000 €$ al Consorcio de Aguas y Residuos de La Rioja. Las razones de la sanción estribaban en el incumplimiento de la autorización de vertidos de aguas residuales al superar el volumen máximo diario autorizado a lo largo de todo el año, y en la realización de vertidos contaminantes no autorizados en época de vendimia. La parte demandante (el Consorcio de Aguas y Residuos de La Rioja) recurre la resolución por entender que esta vulnera: 1) el principio de tipicidad; 2) el principio de personalidad; 3) el principio de presunción de inocencia; y 4) el principio de proporcionalidad.

En cuanto a la vulneración del principio de tipicidad, el TSJLR señala que en el pliego de cargos de los servicios de inspección se señalan como vulnerados los artículos 116.3.c), 116.3.f) y 116.3.g) del Real Decreto Legislativo 1/2001, de 20 de julio, así como los artículos 315.b), 315 I) y 315 i) del Real Decreto $849 / 1986$, preceptos estos en los que se recogen las infracciones de las que se acusa a la parte demandante. Asimismo, el TSJLR puntualiza que los hechos 
infractores quedan redactados de una forma clara, y no vaga, en el pliego de cargos. Por lo que se refiere a la vulneración del principio de personalidad de las infracciones y sanciones, la parte demandante argumenta que la infracción por alivios de aguas residuales al colector que se le imputan, fueron realizadas por bodegas en épocas de vendimia. Sin embargo, el TSJLR señala que el artículo 116.3 del Real Decreto Legislativo 1/2001, también preceptúa el incumplimiento de sus obligaciones si se debieron a una actuación de omisión. En este sentido, dado que la demandante tiene competencia en materia de recogida de tratamiento de residuos puede imponérsele tal sanción por comisión por omisión de la infracción. Esto no impediría, tal y como señala el TSJLR que, además, se pudiese sancionar a otros coautores por sus actuaciones, en este caso, activos.

Respecto de la tercera causa de recurso, esto es, la vulneración del principio de presunción de inocencia, el TSJLR responde al demandante que los hechos infractores de los que se le acusa fueron verificados por una visita de inspección y recogidos en los correspondientes informes, dotándose a dichos hechos, en aplicación del artículo 25 de la Ley 40/2015, de presunción de veracidad. Además, apunta el tribunal que la demandante no ha presentado prueba en contrario. Finalmente, en cuanto a la vulneración del principio de proporcionalidad de la sanción, la parte demandante entiende que no se han tenido en cuenta diversos factores que el artículo 117.1 del Real Decreto Legislativo 1/2001 permiten disminuir la sanción, como la repercusión en el orden y aprovechamiento del dominio público hidráulico, la afectación a la seguridad de las personas y bienes, las circunstancias del responsable, su grado de malicia, participación y beneficio obtenido, así como el deterioro producido en la calidad del recurso. Por el contrario, el TSJLR remarca que, habiéndosele impuesto una sanción de $4.000 €$ por una infracción leve que puede ser sancionada con hasta $10.000 €$, la multa no es desproporcionada. De hecho, señala el TSJLR, la sanción ha sido impuesta dentro de la mitad inferior de la pena de multa.

Por todo ello, el TSJLR desestima el recurso contencioso-administrativo interpuesto por el Consorcio de Aguas y Residuos de La Rioja. 


\section{CAZA}

En el periodo objeto de recopilación el TSJLR ha dictado dos sentencias cuya materia genérica objeto de disputa ha sido el derecho sancionador en el ámbito de caza. En ambas se confirman las sanciones impuestas a tres personas (si bien, solo una de ellas es la que recurre en cada una de las sentencias) por llevar a cabo la modalidad de "caza de gancho de caza mayor» sin autorización y por negarse a entregar la pieza de caza abatida ${ }^{1}$. Las alegaciones de las partes demandantes, en ambos casos, no son acogidas por el tribunal porque las pruebas presentadas por las mismas no prueban, a juicio del mismo, que no se hubiesen producido los hechos señalados por los agentes forestales. La prueba consistió en la comparecencia de testigos y, según se relata en la sentencia, sus declaraciones fueron contradictorias².

\footnotetext{
${ }^{1}$ Arts. 81.19 y 82.29 Ley 9/1998, de 2 de julio, de Caza de La Rioja.

${ }^{2}$ SSTSJLR 366/2018, de 21 de junio y 319/2018 de 28 de junio.
} 